\section{All at sea - and up in the air}

\section{Henry Charnock}

Elements of Dynamic Oceanography. By David Tolmazin. Allen \& Unwin: 1985. Pp.181. Hbk £25, \$39.95; pbk £11.95, $\$ 19.95$.

Introductory Physics of the Atmosphere and Ocean. By L. Hasse and F. Dobson. Reidel: 1986. Pp.126. Dfl. 57, \$19.95, £15.95.

THE complicated motion of our turbulent, stratified, rotating (and ill-observed) ocean presents problems among the most difficult in fliuid mechanics. To deal with them in words and pictures, without mathematical formalism, is a formidable task. But Professor Tolmazin has to a large extent succeeded in communicating his enthusiasm about ocean circulation with only few equations. Perhaps his book should have been subtitled, like one of Auden's, The Romantic Iconography of the Sea: the first words of Tolmazin's preface are "The ocean evokes the most romantic images of nature".

So far as there is a unifying image in the book, it is the Stommel paradigm originally associated with explaining the westward intensification of ocean boundary currents: Tolmazin deals with the general meridional flows due to the curl of the windstress, with currents such as the Gulf Stream, with the analogous western boundary currents at great depth and with the meso-scale eddies that have been such a feature of recent studies. But there is much more in his book than a simplified account of the development of ocean circulation research over the past 50 years there are sections on turbulence (including Kolmogoroff's theory of locally isotropic turbulence) and on recent developments in observing techniques such as satellite altimetry and acoustic tomography, as well as descriptions of more classical instruments, observations and interpretations.

In places the reader is expected to take too much on faith (in deriving the Richardson number, for example, is it really "natural to assume that the kinetic energy of a particle is proportional to its density and the vertical velocity gradient"?), and the explanatory comments sometimes seem unnecessarily picturesque (do trains in the Northern Hemisphere really wear the right-hand rail faster than the left?). Some of the background material is not quite up to date (the definition of salinity, for example), and there are some minor errors and a number of misprints, but the book generally succeeds in communicating the fascination of a rapidly developing subject. Moreover it

will be of interest to established Western oceanographers because it has many references to Soviet research; the author was until a few years ago an active researcher in the Soviet Union, as will be seen from some of his illustrations and from his occasional use of an unusual word or sentence.

Oddly enough, Tolmazin's basically descriptive book would be more appropriately entitled Introductory Physics of the Ocean, while those of Hasse and Dobson (there are two essentially separate sections bound together) would be more accurately described as Elements of the Physics of the Atmosphere and Ocean. Both Hasse and Dobson start from the basic building blocks of meteorology and physical oceanography, and go on to provide much-condensed accounts of atmospheric and oceanic processes, assuming that the reader is familiar with the

\section{Climatology snapped}

\section{T.M.L. Wigley}

World Climatic Systems. By John G. Lockwood. Edward Arnold: 1985. Pp.292. Pbk $£ 17.50, \$ 29.50$.

Climatology has become like the Hydra, the creature itself being the climate system and each head, in Lockwood's terminology, being a subsystem. Lockwood has taken on the Heraclean labour of attempting to describe the beast by photographing all the heads at once. This is a difficult task, now more than ever because the subject is a target moving with increasing speed. Is the present book a success? Certainly most of the heads have been, if not completely captured, at least quite interestingly portrayed.

The book is directed towards secondand third-year university and polytechnic students in geography, environmental science and related subjects such as agriculture and hydrology (the latter field, surprisingly, is not mentioned in the preface, even though it is a major component of the text). It is divided into two parts, a large section on the climate systems and a smaller one on climatic impacts. The first part considers the atmospheric, oceanic, cryospheric and land-surface subsystems separately (with the land-surface further divided into arid, grassland and forest subsystems). The second unfortunately seems to have been rather an afterthought, and covers only climate and energy, and climate and food (ignoring the impact of climate on water resource (sub)systems, although this topic is covered to some degree in various places in the climatic system section).

The structure of the book is sensible and attractive. The execution is less good, mathematics and physics involved. For example, the equations of motion, in tensor notation, are presented in Hasse's first few pages while the last 16 of Dobson's part of the book are devoted to an expert summary of the dynamics of sea surface waves. This is because both sections were originally presented as introductory material to a conference of physicists and chemists concerned with air/sea transfer processes.

It seems unlikely that these two accounts will be accessible to readers not already familiar with the subject. However they may well provide a useful reference summary for fluid dynamicists and physicists seeking an indication of how their specialities can be applied to the atmosphere and the ocean.

Henry Charnock is a Professor in the Depart. ment of Oceanography, University of Southampton, Southampton SO9 $5 \mathrm{NH}, \mathrm{UK}$.

simply because of the breadth of material that must be covered. Consequently, the writing is very dense and at times superficial, especially in the impact section. Much of the content is too obviously derivative ("according to..." is one of the author's favourite phrases) and, as a result, the cited material tends to be reviewed uncritically. On the other hand, the coverage is impressive and the references are extensive and reasonably up to date (although published in 1985, most of the sources mentioned come from the years up to and including 1983).

There are a few errors of fact, most of them of no importance, but still reprehensible. More annoying to the climatological community are the omissions; very few of the priorities identified by the World Climate Programme are covered well, if at all, while too much space is devoted to Lockwood's own particular interest in hydrological runoff modelling. The balance of the book would therefore appeal less to those climatologists whose background is in meteorology. When compared, for example, with The Global Climate (edited by J.T. Houghton and published by Cambridge University Press in 1984 and again in paperback last year) one finds little overlap, although this is not necessarily a bad thing.

This is not an inspiring book like Schneider and Londer's The Coevolution of Climate and Life (see Nature 310, 517; 1984 ), but it is a valuable, workmanlike addition to the climatological literature. As a "snapshot", it provides a reasonable balance between scope and resolution and should give students a good feeling for both the breadth of disciplines that climatology now embraces, and the complexities within each of them.

T.M.L. Wigley is Director of the Climatic Research Unit, University of East Anglia, Norwich NR4 7TJ, UK. 